\title{
Mitochondrial genomes of acrodont lizards: timing of gene rearrangements and phylogenetic and biogeographic implications
}

\author{
Yasuhisa Okajima1,2 and Yoshinori Kumazawa*2
}

\begin{abstract}
Background: Acrodonta consists of Agamidae and Chamaeleonidae that have the characteristic acrodont dentition. These two families and Iguanidae sensu lato are members of infraorder Iguania. Phylogenetic relationships and historical biogeography of iguanian lizards still remain to be elucidated in spite of a number of morphological and molecular studies. This issue was addressed by sequencing complete mitochondrial genomes from 10 species that represent major lineages of acrodont lizards. This study also provided a good opportunity to compare molecular evolutionary modes of mitogenomes among different iguanian lineages.
\end{abstract}

Results: Acrodontan mitogenomes were found to be less conservative than iguanid counterparts with respect to gene arrangement features and rates of sequence evolution. Phylogenetic relationships were constructed with the mitogenomic sequence data and timing of gene rearrangements was inferred on it. The result suggested highly lineage-specific occurrence of several gene rearrangements, except for the translocation of the tRNAPro gene from the 5 ' to 3 ' side of the control region, which likely occurred independently in both agamine and chamaeleonid lineages. Phylogenetic analyses strongly suggested the monophyly of Agamidae in relation to Chamaeleonidae and the nonmonophyly of traditional genus Chamaeleo within Chamaeleonidae. Uromastyx and Brookesia were suggested to be the earliest shoot-off of Agamidae and Chamaeleonidae, respectively. Together with the results of relaxed-clock dating analyses, our molecular phylogeny was used to infer the origin of Acrodonta and historical biogeography of its descendant lineages. Our molecular data favored Gondwanan origin of Acrodonta, vicariant divergence of Agamidae and Chamaeleonidae in the drifting India-Madagascar landmass, and migration of the Agamidae to Eurasia with the Indian subcontinent, although Laurasian origin of Acrodonta was not strictly ruled out.

Conclusions: We detected distinct modes of mitogenomic evolution among iguanian families. Agamidae was highlighted in including a number of lineage-specific mitochondrial gene rearrangements. The mitogenomic data provided a certain level of resolution in reconstructing acrodontan phylogeny, although there still remain ambiguous relationships. Our biogeographic implications shed a light on the previous hypothesis of Gondwanan origin of Acrodonta by adding some new evidence and concreteness.

\section{Background}

Acrodonta is a group of squamate lizards that have the characteristic acrodont dentition. Acrodonta consists of two families, Agamidae and Chamaeleonidae, while Pleurodonta having the pleurodont dentition includes Iguanidae sensu lato [1]. These three families are extant related

\footnotetext{
*Correspondence: kuma@nsc.nagoya-cu.ac.jp

2 Department of Information and Biological Sciences, Graduate School of Natural Sciences, Nagoya City University, 1 Yamanohata, Mizuho-cho, Mizuhoku, Nagoya 467-8501, Japan

Full list of author information is available at the end of the article
}

members of the infraorder Iguania [2], containing approximately 1,500 species in the world [1]. They are mainly dendrophilous or ground living, and herbivorous or insectivorous animals. Agamids show a certain level of morphological convergence with iguanids whereas chamaeleonids are morphologically quite unique in various organs, such as eye, tongue, tail, and toe [1]. In contrast to the mainly New World distribution of Iguanidae, extant acrodont families are distributed primarily in tropical or subtropical regions of the Old World [1]. Agamids are widely distributed in Asia (including Indoaustralian 
Archipelago), Australasia and Africa. Chamaeleonids can be seen in Africa (including islands off East Africa), Madagascar, Middle East, Spain, and South Asia.

Phylogenetic relationships between iguanian lizards have been studied both morphologically [2-9] and molecularly [10-18]. These studies are in agreement with one another with respect to the monophylies of Acrodonta (Agamidae + Chamaeleonidae) and Chamaeleonidae. However, the monophyletic status of both Iguanidae and Agamidae is still under debate and these families have often been treated as metataxa (e.g., $[2,3,10])$. Within the families Agamidae and Chamaeleonidae, morphological studies identified several groups that nearly correspond to agamid subfamilies [3] and chamaeleonid genera [5]. However, the interrelationships of these relatively deepbranch clades have not been settled yet even by the molecular studies that combined a few genes from mitochondrial and/or nuclear genomes. Collection of more nucleotide sites may help to increase resolution in phylogenetic analyses.

Complete mitochondrial genomes may be a target for this purpose because they provide ample nucleotide sites with straightforward sequencing and analytical procedures (see, e.g., [19]) and because they are relatively free from DNA recombinations and gene duplications/deletions [20], albeit with some criticisms on the close genetic linkages of mitochondrial genes, potential saturation of rapidly evolving sites, and occasional strong positive selections [21]. Vertebrate mitochondrial DNAs (mtDNAs) are $16-18 \mathrm{kbp}$ double-stranded circular DNAs, which encode 37 genes for 22 tRNAs, 2 rRNAs, and 13 proteins together with a major noncoding region or control region $(\mathrm{CR})$ that is believed to regulate replication and transcription of the mtDNA [20,22]. The gene organization of these encoded genes and the CR is usually very conservative but, in some groups such as Agamidae, gene rearrangements have been reported [23-25]. Why the evolution of mitochondrial genomes is less conservative in some lineages with respect to rates of changes in the sequence and the gene arrangement is still an open question.

When we started this study, complete or nearly complete mtDNA sequences were known from four agamids [24-27] and one chamaeleonid [28]. Macey et al. [29] later added more than a dozen of chamaeleonid taxa mostly from genus Chamaeleo. In this study, we collected additional mitogenomic sequences from taxa that represent major groups of Agamidae and Chamaeleonidae. Using these molecular data, we addressed to clarify 1) frequency and timing of the gene rearrangements, 2) phylogenetic relationships among major acrodont groups, and 3) historical biogeography of acrodont lizards in their higher taxonomic level.

\section{Results}

\section{Mitogenomic features of Acrodonta}

Complete or nearly complete mtDNA sequences of 5 agamid and 5 chamaeleonid species were determined for this study (Table 1). These sequences, together with previously reported mitogenomic sequences for 4 agamids [24-27] and 7 chamaeleonids [28,29], were used to characterize features of acrodontan mitogenomes. The acrodontan mitogenomes contained 37 genes that show clear sequence similarity to corresponding mitochondrial genes from other vertebrates. Anticodon sequences of tRNA genes were identical to those of other vertebrates with an exception.

The anticodon triplet sequence of mitochondrial

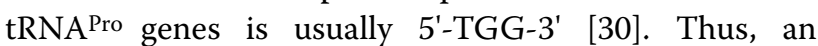
unmodified uridine is likely to be present at the first anti-

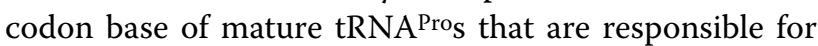
decoding all four CCN codons [31]. So far, only unmodified uridine in this position is considered to be capable of pairing with all four bases at the third codon positions, while modification of the uridine leads to decoding only partial codon members of the 4-codon boxes [31]. Calotes versicolor, a member of Draconinae, had the 5'TGG-3' anticodon in the tRNAPro gene. However, Acanthosaura armata, another representative of Draconinae, was found to have a 5'-CGG-3' anticodon. This is not a sequencing error, for the same 5'-CGG-3' sequence was found in the second individual of $A$. armata and an individual of Acanthosaura lepidogaster (data not shown). At present, we do not know how the CCN codons, all of which appear frequently in protein-coding genes of $A$. armata mtDNA, are decoded by products of this aber-

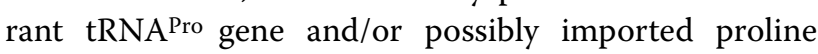
tRNAs from cytosol. Unknown modification or editing starting from cytidine at the first anticodon position may be responsible for this.

Figure 1 summarizes gene arrangement changes found in acrodontan mitogenomes. First, all these mitogenomes shared a tRNA gene rearrangement from IQM to QIM [23] that is not present in the iguanid mitogenomes $[18,32,33]$, supporting that this gene rearrangement took place in the ancestral acrodontan lineage after its divergence from Iguanidae [23].

Acrodontan mitogenomes show extensive variations in the location and orientation of the tRNA Pro gene, which is typically encoded by the light strand and located between the tRNA ${ }^{\text {Thr }}$ gene and the CR in most other vertebrates (Fig. 1). All the chamaeleonids examined possess the tRNA ${ }^{\text {Pro }}$ gene at the 3 ' side of the CR, 200-400 bp 5' to the tRNA ${ }^{\text {Phe }}$ gene (see Fig. 2 and Additional File 1). The trans-

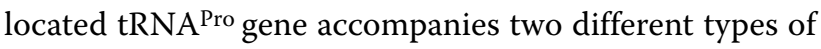
AT-rich regions around it (see below). Among agamids,

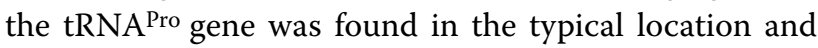


Table 1: Iguanian taxa analyzed for their complete mtDNA sequence in this study

\begin{tabular}{|c|c|c|c|c|c|}
\hline Scientific name & Accession No. & mtDNA length (bp) & CR length (bp) & Voucher No. & Reference \\
\hline \multicolumn{6}{|l|}{ Family Agamidae } \\
\hline Uromastyx benti & AB114447 & 16380 & 990 & NSMT-H4670 & this study ${ }^{1}$ \\
\hline Leiolepis guttata & AB476400 & 16552 & 1167 & NUM-Az389 & this study ${ }^{1}$ \\
\hline Pogona vitticeps & AB166795 & 16751 & 798 & NUM-Az383 & Amer and Kumazawa [25] \\
\hline Chlamydosaurus kingii & EF090422 & 16761 & 812 & - & Ujvari et al. [27] \\
\hline Hydrosaurus amboinensis & AB475096 & 16129 & 823 & SDNCU-x029 & this study \\
\hline Calotes versicolor & AB183287 & 16670 & 1504 & NUM-Az382 & Amer and Kumazawa [24] \\
\hline Acanthosaura armata & AB266452 & 16544 & 1463 & NSMT-H4595 & this study ${ }^{1}$ \\
\hline Pseudotrapelus sinaitus & AB262447 & 16560 & 1456 & - & this study ${ }^{1}$ \\
\hline Xenagama taylori & DQ008215 & 16220 & 1174 & CAS225502 & Macey et al. [26] \\
\hline \multicolumn{6}{|l|}{ Family Chamaeleonidae } \\
\hline Calumma parsonii & AB474915 & 17497 & 2182 & SDNCU-x030 & this study \\
\hline Trioceros melleri & AB474916 & 16832 & 1521 & SDNCU-x031 & this study \\
\hline Chamaeleo calcaricarens & EF222195 & 17451 & 2189 & CAS225435 & Macey et al. [29] \\
\hline Chamaeleo chamaeleon & EF222201 & 17415 & 2155 & CAS217781 & Macey et al. [29] \\
\hline Chamaeleo calyptratus & EF222192 & 17433 & 2178 & MVZ236475 & Macey et al. [29] \\
\hline Chamaeleo zeylanicus & EF222191 & 18923 & 3665 & MVZ248409 & Macey et al. [29] \\
\hline Chamaeleo monachus & EF222190 & 18900 & 3672 & MVZ236484 & Macey et al. [29] \\
\hline Chamaeleo dilepis & EF222189 & 17875 & 2618 & CAS168922 & Macey et al. [29] \\
\hline Furcifer oustaleti & AB185326 & 18021 & 2785 & NUM-Az380 & Kumazawa [28] \\
\hline Kinyongia fischeri & AB474917 & $17400^{*}$ & - & SDNCU-x032 & this study \\
\hline Rieppeleon kerstenii & AB474918 & $17982^{*}$ & - & SDNCU-x033 & this study \\
\hline Brookesia decaryi & AB474914 & 17324 & 2094 & SDNCU-x034 & this study \\
\hline \multicolumn{6}{|l|}{ Family Iguanidae } \\
\hline Anolis cybotes & AB218960 & $17853^{*}$ & - & NSMT-H4587 & Okajima and Kumazawa [18] \\
\hline Basiliscus vittatus & AB218883 & 16948 & 1562 & NSMT-H4588 & Okajima and Kumazawa [18] \\
\hline Gambelia wislizenii & AB218884 & 17563 & 2181 & NSMT-H4589 & Okajima and Kumazawa [18] \\
\hline Iguana iguana & AJ278511 & 16633 & 1191 & - & Janke et al. [32] \\
\hline Oplurus grandidieri & AB218720 & 17122 & 1758 & NSMT-H4590 & Okajima and Kumazawa [18] \\
\hline $\begin{array}{l}\text { Chalarodon } \\
\text { madagascariensis }\end{array}$ & AB266748 & 16851 & 1493 & NSMT-H4591 & Okajima and Kumazawa [18] \\
\hline Polychrus marmoratus & AB266749 & 17743 & 2371 & NSMT-H4592 & Okajima and Kumazawa [18] \\
\hline Leiocephalus personatus & AB266739 & 16681 & 1316 & NSMT-H4593 & Okajima and Kumazawa [18] \\
\hline Plica plica & AB218961 & $17643^{*}$ & - & NSMT-H4594 & Okajima and Kumazawa [18] \\
\hline Sceloporus occidentalis & AB079242 & 17072 & 1689 & - & Kumazawa [33] \\
\hline
\end{tabular}

Asterisks for the mtDNA length represent values for nearly complete mitogenomes with imcomplete CR sequences. The length of CR does not include that of tRNAPro gene for chameleons.

${ }^{1}$ Mitochondrial genome sequences for these taxa were originally determined by Dr. Sayed A. M. Amer and provided for this study through his courtesy.

Abbreviations for museums are: NSMT, National Science Museum, Tokyo; NUM, Nagoya University Museum; SDNCU, Specimen Depository of the Graduate School of Natural Sciences, Nagoya City University; CAS, California Academy of Science; and MVZ, Museum of Vertebrate Zoology, University of California at Berkeley. 
orientation for representatives from Uromastycinae, Leiolepidinae, Amphibolurinae and Hydrosaurinae. Two representatives from Draconinae (C. versicolor and $A$. armata) had an inverted tRNAPro gene (i.e., the switch of an encoded strand from $\mathrm{L}$ to $\mathrm{H}$ without changing its relative location to other genes and the CR), which was originally found by Amer and Kumazawa [24]. Finally, the

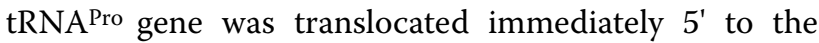

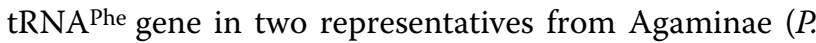
sinaitus and $X$. taylori)[26]. Thus, these anomalies in the

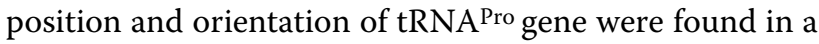
lineage specific manner. Another example of specific changes in the gene arrangement or features was seen in two representatives from Australasian agamid subfamily Amphibolurinae ( $P$. vitticeps and $C$. kingii), in which duplicate CR sequences are inserted between ND5 and ND6 genes [25,27]. On the other hand, the characteristic stem-and-loop structure for the putative light-strand replication origin is known to have disappeared from the WANCY tRNA gene cluster in multiple agamid lineages [34]. Among the 31 iguanian taxa examined, all iguanid and chamaeleonid taxa retained this structure, whereas Uromastyx benti, Hydrosaurus amboinensis and two amphibolurine agamids did not have it.

Control regions of chamaeleonid mitogenomes were considerably longer than agamid and iguanid counterparts. The average length of the CR was $2506 \mathrm{bp}$ among 10 chameleons, while that was 1132 and $1695 \mathrm{bp}$, respectively, among 9 agamids and 8 iguanids (Table 1). Figure 2 shows the schematic diagram of the chamaeleonid CRs. As seen for mammals (e.g., [35]), Domain 1 contains ETAS (extended termination associated sequences) elements and tandemly repeated sequences. Domain 2 contains the central conserved region in which conserved boxes C, D and F [36] are identified (Fig. 2 and Additional File 1). Domain 3 contains conserved sequence blocks (CSBs) I and III [37] and two types of AT-rich sequences. The first type, that occurs 5 to the tRNA ${ }^{\text {Pro }}$ gene, is characterized by repetition of a stretch of $A$ followed by a stretch of $\mathrm{T},\left(\mathrm{A}_{\mathrm{x}} \mathrm{T}_{\mathrm{y}}\right)_{\mathrm{n}}$, and the second type found mostly $3^{\prime}$ to the tRNAPro gene (except for Brookesia decaryi in which it also occurs $5^{\prime}$ to the tRNA ${ }^{\text {Pro }}$ gene) is a repetition of an AT sequence, $(\mathrm{AT})_{\mathrm{n}}$. Although these two types can also be seen in non-chamaeleonid CRs (see, e.g., [38]), they occur in chamaeleonids in much larger scales. Moreover, chameleon CRs, except for T. melleri, were found to have a long array of tandemly repeated sequences 5 ' to the ETAS regions in Domain 1 (Additional File 1). Taken together, the expanded size of chamaeleonid CRs is primarily due to tandem repetitions in Domain 1 but this is also due to the extensive arrays of the two types of ATrich sequences in Domain 3.

\section{Phylogenetic analyses}

Figure 3 shows a Bayesian tree constructed using mitogenomic nucleotide sequences. Non-iguanian parts of the tree were largely consistent with results by previous studies using mitochondrial [28,39] and nuclear [16,40-42] gene sequences. Four saurian infraorders (Iguania, Gekkota, Scincomorpha and Anguimorpha) were recognized but Iguania did not represent the earliest shoot-off among them in sharp contrast with conclusions from morphological studies [2,9]. Iguania consistently clusters with Anguimorpha in these molecular studies including ours. As reported previously [18], Madagascan oplurine iguanids (i.e., Oplurus grandidieri and Chalarodon madagascariensis) diverged first within Iguanidae sensu lato, forming a sister group of other Neotropical iguanids.

Iguanidae forms a sister group of Acrodonta in which Agamidae and Chamaeleonidae are both monophyletic and sister to each other (Fig. 3). These results were supported with 1.00 Bayesian posterior probability (Bayes$\mathrm{PP})$ and $100 \%$ maximum likelihood (ML) bootstrap values. Macey et al. [13] recognized 6 major clades in Agamidae and considered them agamid subfamilies, from which the present study includes 1-2 representative species. Within Agamidae, Uromastyx benti (Uromastycinae) diverged first and Leiolepis guttata (Leiolepidinae) diverged next (Fig. 3). Uromastycinae and Leiolepidinae have often been considered to be sister to each other, making a basal clade in Agamidae [4,7,43]. Among the other four agamid subfamilies, two representatives from Amphibolurinae diverged first, followed by Hydrosaurus amboinensis (Hydrosaurinae) and finally by two representatives from each of Agaminae and Draconinae (Fig. 3).

Twelve representative species that cover all 6 traditional genera of Chamaeleonidae were sampled in this study: Brookesia, Rhampholeon (now divided into Rhampholeon and Rieppeleon [44]), Calumma, Furcifer, Bradypodion (now divided into Bradypodion, Kinyongia and Nadzikambia [45]) and Chamaeleo (now divided into Chamaeleo and Trioceros [46]). Our tree (Fig. 3) shows that Brookesia decaryi and Rieppeleon kerstenii represent basal chamaeleonid lineages but that they are not sister to each other. Our tree also shows non-monophyly of the traditional genus Chamaeleo. Six hornless species in the traditional subgenus Chamaeleo (now genus Chamaeleo [46]) appeared in an entirely different position from horned Trioceros melleri. T. melleri forms a sister group of Calumma parsonii and Furcifer oustalleti and all these three taxa cluster with Kinyongia fischeri with the exclusion of the 6 hornless Chamaeleo species.

Previous studies $[16,28,39]$ suggested highly accelerated molecular evolutionary rates of acrodontan mitochondrial genes. This tendency was conspicuous for almost all lineages of acrodonts and reflected by considerably lon- 


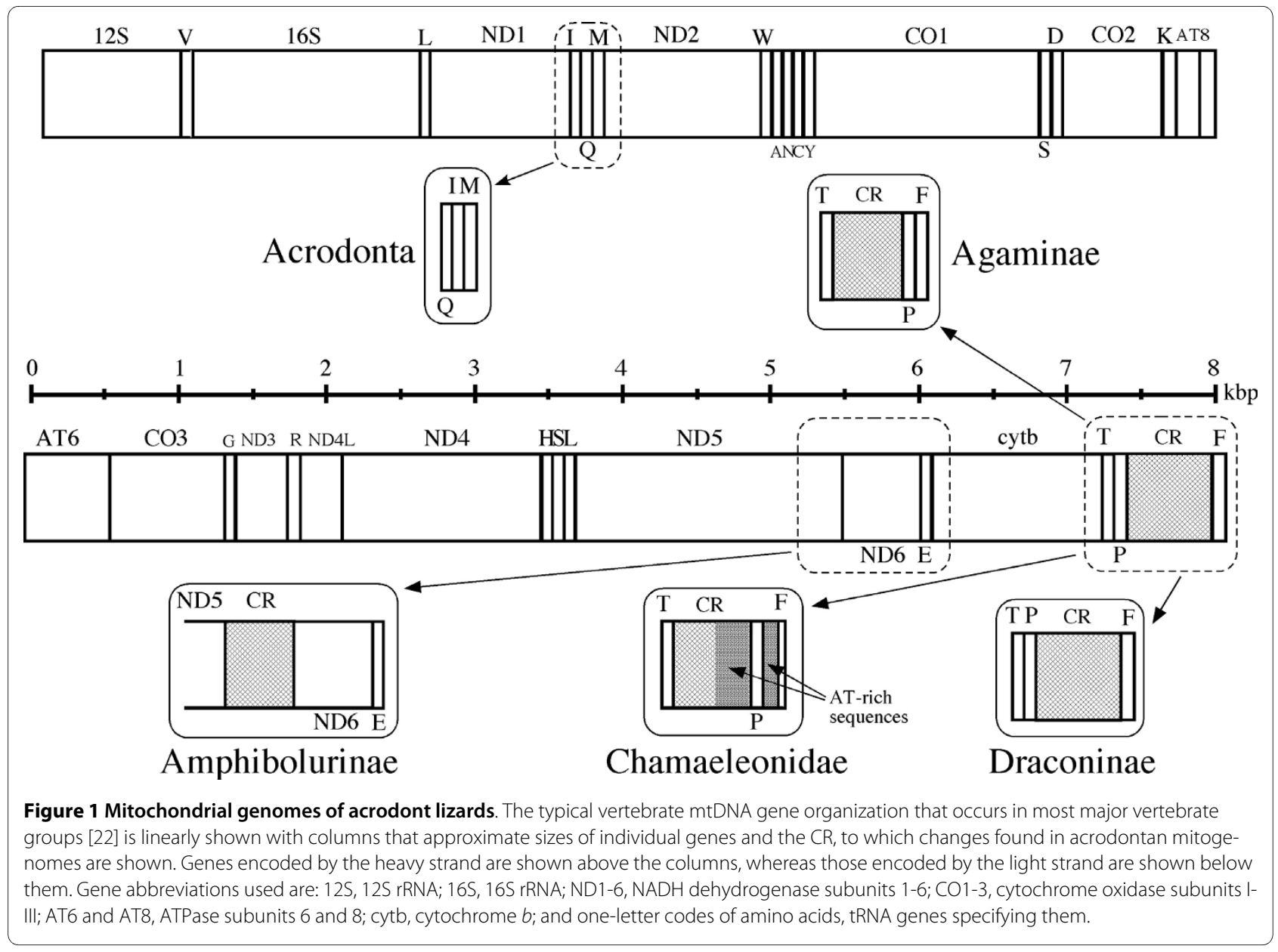

ger branches for acrodonts as compared to those for iguanids (Fig. 3).

\section{Divergence times}

Figure 4 shows divergence times estimated using the mitogenomic dataset. Although there are not many squamate fossil records that can effectively constrain lower and upper boundaries of divergences [47], we included some available ingroup calibrations inside Squamata in addition to relatively solid fossil-based calibrations outside Squamata. The use of the relaxed-clock method for divergence time estimation [48] seems necessary in light of the heterogeneity of molecular evolutionary rates

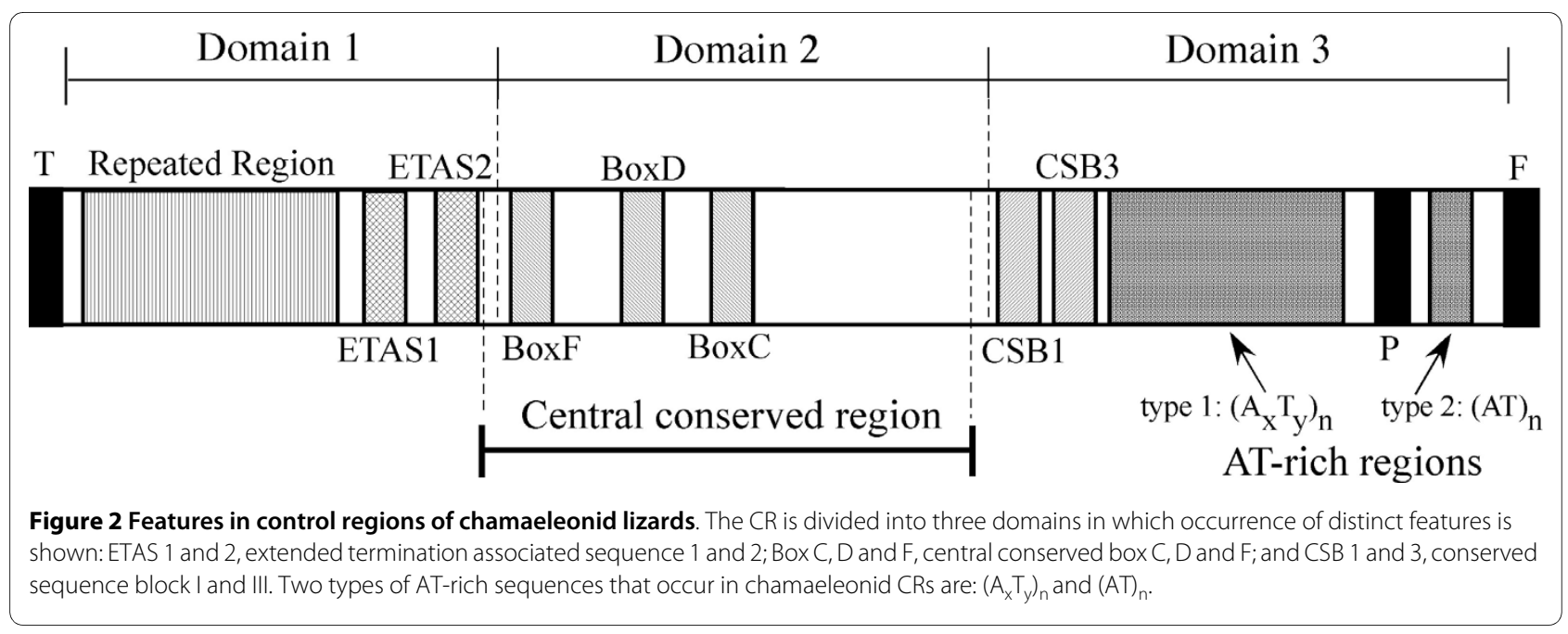




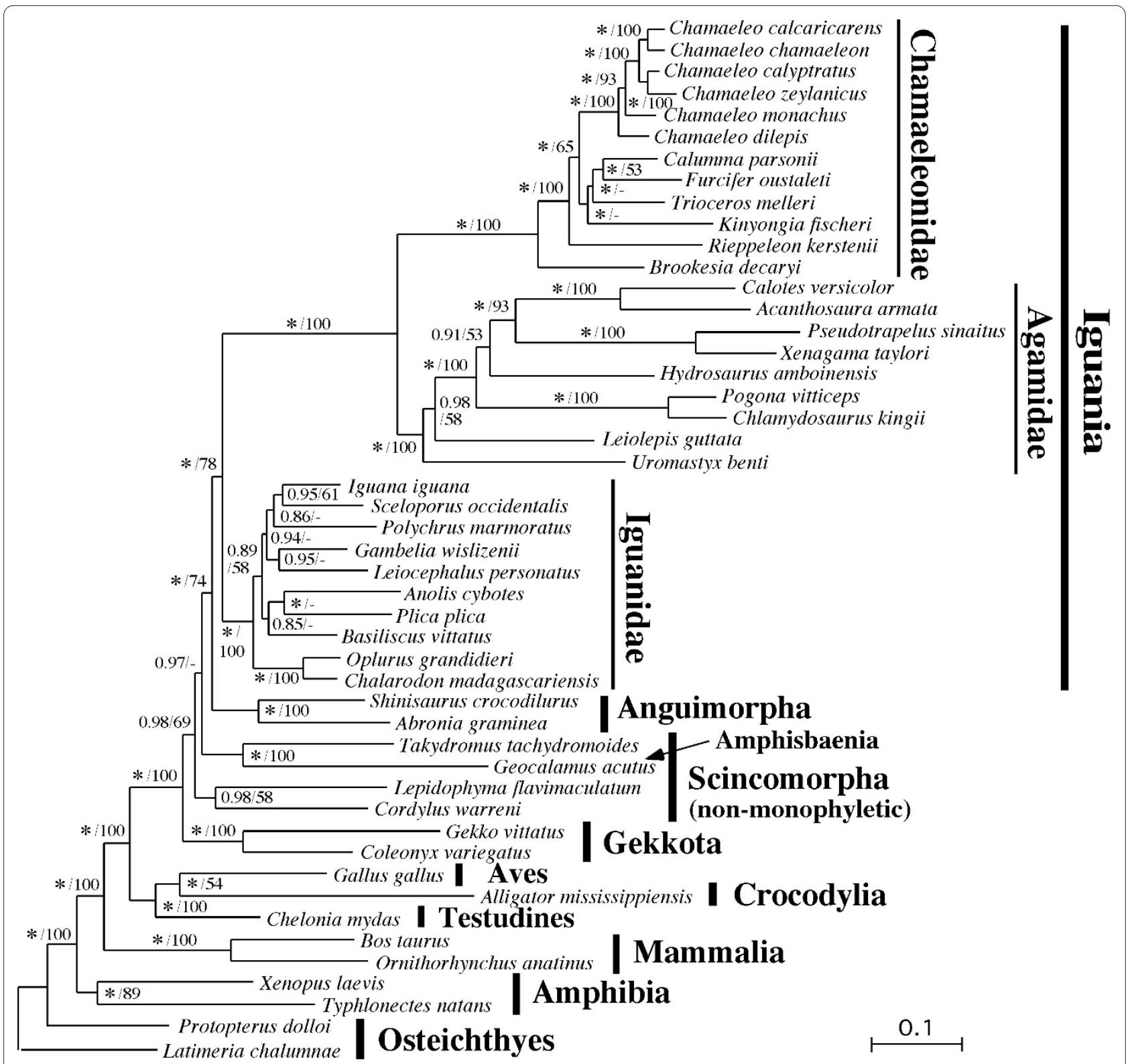

Figure 3 A Bayesian tree reconstructed using mitogenomic nucleotide sequences. Values to the left and right of slashes are Bayes-PP and ML bootstrap values (only for those larger than 50\%), respectively. An asterisk for the posterior probabilities stands for 1.00. See Table 1 and Additional File 3 for accession numbers of mitogenomic sequences for individual taxa.

across lineages as seen by considerably longer and shorter branch lengths from the root to tips (Fig. 3).

The results suggest Triassic-Jurassic [186-220 million years ago (MYA) for the $95 \%$ credibility range] divergence of Acrodonta from Iguanidae but much younger midCretaceous (96-122 MYA) divergence into Agamidae and Chamaleonidae (Fig. 4). Agamid subfamilies may have separated during Late Cretaceous times while chamaeleonid radiations into extant genera were estimated to have occurred in the Cenozoic after the K/T boundary. Among the time constraints used in the divergence time estima- tion, only the $5<\mathrm{T}<13$ MYA divergence between African and Arabian Chamaeleo species was based on a biogeographic assumption. In order to evaluate effects of this ingroup calibration on divergence time estimation, we also conducted the multidistribute analysis without this constraint. The resultant divergence times at various iguanian nodes (data not shown) were very similar to those obtained including this biogeographic constraint (Fig. 4), supporting its congruence with other older time constraints based on fossil evidence. 
Recent molecular dating with multiple nuclear genes (reviewed in [42]), though based on different dating methods and time constraints, suggested somewhat younger dates for the divergence of Acrodonta from Pleurodonta ( 145 MYA) and the separation into Agamidae and Chamaeleonidae ( 85 MYA). However, there is some topological difference between the studies (e.g., nonmonophyly of Agamidae in [41]) and several different analyses could provide at most 20 million years of confidence interval in each side of the best time estimate [41]. Thus, the nuclear time estimates for the AgamidaeChamaeleonidae split may partly overlap our mitochondrial estimate (96-122 MYA, Fig. 4).

\section{Discussion}

\section{Structural evolution of acrodontan mitogenomes}

In the present study, mitogenomic sequences were collected from major representative lineages of Acrodonta to provide an opportunity to compare mitogenomic structures among three iguanian families. Iguanid mitogenomes were very conservative with no gene rearrangements. They also appear to have evolved much more slowly than agamid and chamaeleonid counterparts as judged from relatively short branch lengths within Iguanidae (Fig. 3). On the other hand, acrodontan (especially agamid) mitogenomes have an entirely different tendency with occasional gene rearrangements and increased molecular evolutionary rates.

In Fig. 5, possible lineages for the mitogenomic reorganizations described here are mapped along the phylogeny based on the parsimony criterion. Although agamid mitogenomes have several examples of gene rearrangements, most of them can be assigned to specific lineages without multiple parallel changes, supporting the rarity and less homoplasious nature of mitochondrial gene rearrangements [22]. The only possible homoplasious change is the translocation of the tRNAPro gene from the $5^{\prime}$ to $3^{\prime}$ side of the CR in both Agaminae and Chamaeleonidae. However, the tRNA ${ }^{\text {Pro }}$ genes in these taxa are placed in a somewhat different genomic context; i.e., neighboring sequences composed of two types of AT-rich sequences are always present in the chamaeleonids (Fig. 2). This supports that translocations of the tRNAPro gene in agamines and chamaeleonids resulted from independent events. Moreover, if this translocation had occurred once in a common ancestral lineage of Agaminae and Chamaeleonidae, multiple reversals to the original location of the tRNA $^{\text {Pro }}$ gene must be assumed in several agamid lineages, which seems unlikely (Fig. 5). Gene rearrangements around the $\mathrm{CR}$ have been shown to occur independently in multiple lineages by the canonical duplication-and-deletion mechanism [22].

To the best of our knowledge, very few studies [38,49] have characterized structural organization and evolution of CRs in lizard mitogenomes. The present study shows that a region encompassing Boxes $\mathrm{C}, \mathrm{D}$ and $\mathrm{F}$ retains a notable similarity among acrodonts and even among diverse groups of vertebrates (Additional File 1). On the other hand, acrodontan CRs do not seem to conserve CSB II in Domain 3 and agamids do not even retain CSB III (Additional File 1). This is in sharp contrast with CRs of several iguanids, gekkonids and lacertids which conserve all three members of CSBs (Additional File 1; [38]), presenting another evidence for more conservative nature of iguanid mitogenomes than acrodontan counterparts.

\section{Phylogenetic relationships}

As outlined earlier, acrodontan phylogeny was originally reconstructed with morphological data, which has been evaluated with molecular data using some mitochondrial and nuclear gene sequences. The present study addressed this issue using the hitherto longest molecular dataset (9,386 bp). As a trade-off of gaining the large number of sites, we had to somewhat sacrifice the depth of taxon sampling. It is thus important to assess monophylies of individual groups in order to interpret our results with respect to subfamilial or generic interrelationships.

Fortunately, previous molecular studies using a number of taxa but less sites provided strong evidence for a number of clades in Agamidae and Chamaeleonidae. For example, Honda et al. [12], Macey et al. [13] and Amer and Kumazawa [50] strongly, in terms of high bootstrap or other tree-support values, suggested monophylies of Uromastycinae, Amphibolurinae, Draconinae and Agaminae within Agamidae. The remaining subfamilies Leiolepidinae and Hydrosaurinae contain limited numbers of extant species and the monophyly of some leiolepidine species was also strongly supported [13]. In addition, the occurrence of subfamily-specific gene rearrangements (Fig. 5; $[24,25]$ ) is consistent with the monophylies of the corresponding groups. Within Chamaeleonidae, recent molecular studies using multiple gene sequences $[46,51]$ supported the monophylies of two of the traditional six genera (i.e., Brookesia and Furcifer). Remaining traditional genera Chamaeleo, Calumma, Bradypodion and Rhampholeon may each be an assemblage of a few monophyletic groups $[14,15,46,51]$ but no definitive conclusion has been obtained on their phylogenetic relationships.

Our mitogenomic tree (Fig. 3) strongly supports the monophyly of Agamidae relative to Chamaeleonidae (1.00 Bayes-PP and 100\% ML-BP values). This is not an artifact due to, e.g., the long branch attraction because all acrodontan lineages appear to possess accelerated molecular evolutionary rates relative to iguanids (Fig. 3). Morphological analyses (e.g., $[7,10])$ and some molecular ones (e.g., $[16,41,52])$ did not support the agamid monophyly while other molecular studies (e.g., $[13,17,53]$ ) did. 


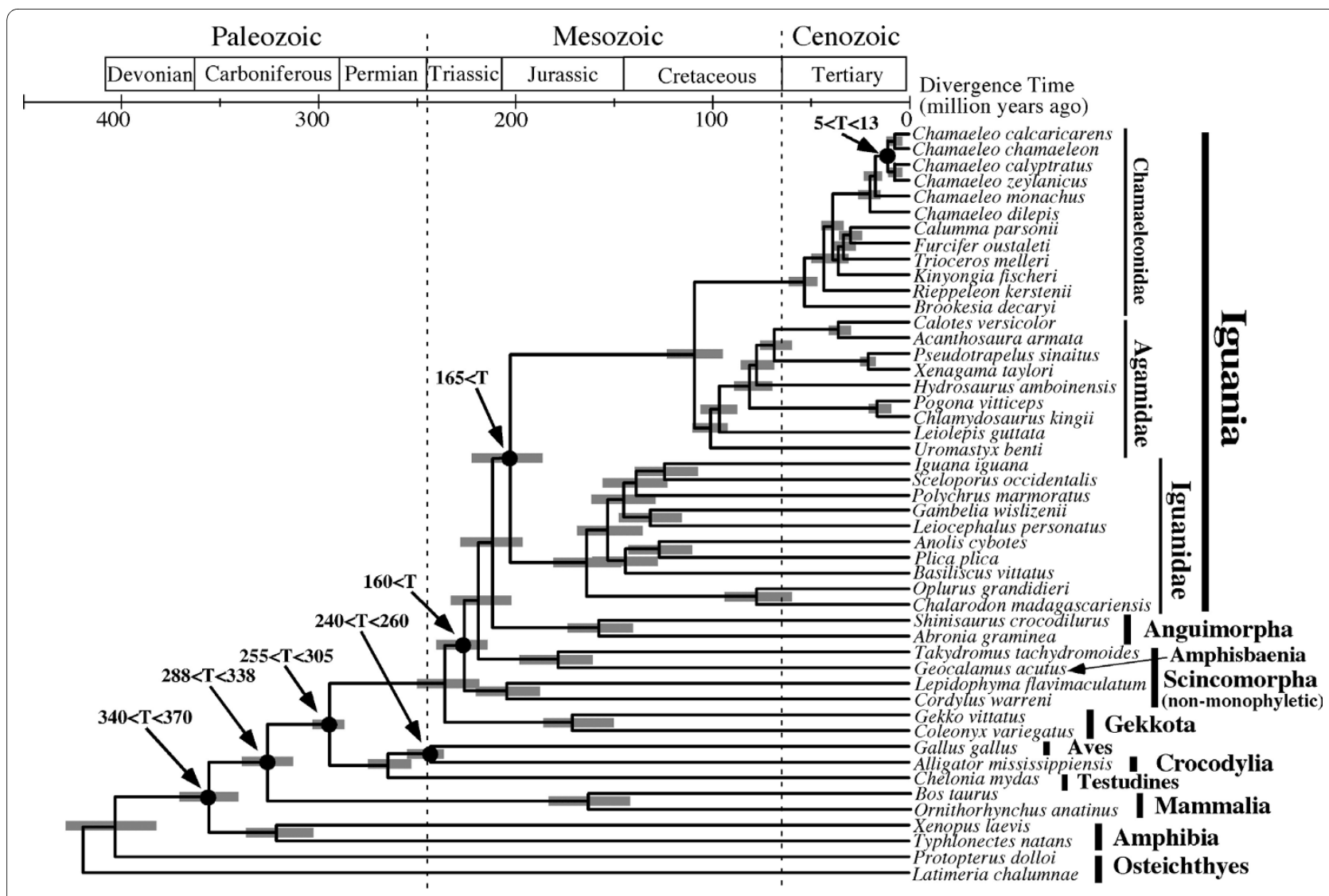

Figure 4 Divergence times estimated by the relaxed-clock dating method. Estimated divergence times at individual nodes are shown with their mean and $95 \%$ credibility ranges (shaded rectangles). Seven time constraints assumed for the time estimation are indicated at the corresponding nodes (see text for more details).

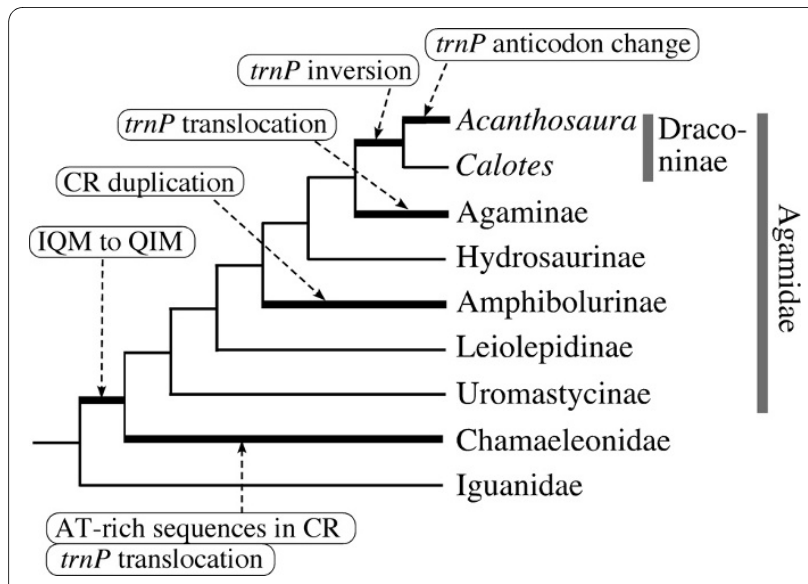

Figure 5 Occurrence of mitogenomic structural changes in acrodont lizards. Lineages on which individual changes occurred were supposed by the parsimony criterion based on the phylogenetic framework (Fig. 3) and distributions of gene arrangements in extant species. See Fig. 1 for actual changes in the gene arrangements. The anticodon change in the tRNAPro gene is TGG to CGG (see text).
Although Agamidae has been regarded as a metataxon under the tentative assumption of its monophyly $[2,3,10]$, this no longer seems necessary in light of our strong molecular evidence on the agamid monophyly.

Mitogenomic data provided agamid subfamilial interrelationships with strong tree-support values in general (Fig. 3). These relationships are consistent with the most parsimonious tree obtained by Macey et al. [13] using $\sim 1,500 \mathrm{bp}$ mitochondrial gene sequences. However, the traditional morphological view tended to unite Uromastyx and Leiolepis into a basal clade (e.g., [3]). The Kishino-Hasegawa test (data not shown) suggested that this sister relationship of Uromastyx and Leiolepis is unlikely, though not rejectable $(p=0.275)$. The sister group relationship of Agaminae and Draconinae is common between morphological [3] and molecular (Fig. 3) results.

Our mitogenomic tree (Fig. 3) was consistent with other molecular studies $[14,46]$ with respect to the most basal divergence of genus Brookesia and the subsequent divergence of the Rhampholeon + Rieppeleon group. However, this phylogenetic relationship was not clear in 
Townsend and Larson [15] who used $~ 1,500$ bp mitochondrial gene sequences for phylogenetic inference. We conducted Bayesian analyses using combined mitochondrial gene sequences that were used by Raxworthy et al. [14] and Townsend and Larson [15] and the results (data not shown) also supported the most basal divergence of Brookesia as shown in Townsend et al. [51]. Although Brookesia (Madagascan leaf chameleons) and Rhampholeon (African leaf chameleons) were once grouped into a common subfamily Brookesiinae [5], another morphological study based on osteological characters [6] suggested the basal divergence of Brookesia alone. Taken together, but primarily based on our mitogenomic phylogeny (Fig. 3), we conclude that the Madagascan Brookesia represents the earliest shoot-off of extant chameleons.

The monophyly of traditional genus Chamaeleo was strongly suggested by morphological analyses based on distinct synapomorphies (e.g., four rotulae in a hemipenis) and it was subsequently supported by a molecular study [14]. However, another molecular study [15] found separate occurrence of its two subgenera (Chamaeleo and Trioceros) in the chamaeleonid phylogeny, albeit with litthe statistical evaluation for their non-monophyly. The most recent molecular study [46] showed stronger evidence for the separation of Chamaeleo and Trioceros, proposing their elevation to distinct genera. Our mitogenomic analyses (Fig. 3) showed that Trioceros melleri is placed distinctly from 6 representatives from Chamaeleo. The Kishino-Hasegawa test rejected $(p=0.017)$ the best tree obtained by constraining the Chamaeleo + Trioceros monophyly (Tree 5 in Table 2, see also Additional file 2). The more conservative Shimodaira-Hasegawa test (Table 2 ) did not reject this tree but its probability was very low $(p=0.137)$, supporting the formal elevation of Chamaeleo and Trioceros to distinct genera [46].

Together with results on testing some specific hypotheses derived from previous morphological and molecular analyses (Table 2), mitogenomic data seem to provide a certain level of resolution on the chamaeleonid phylogeny. To the best of our knowledge, clustering of Furcifer with a group of Calumma containing C. parsonii (Fig. 3) was not suggested by previous studies. Nor was clustering of these two taxa with Trioceros (Fig. 3). Evaluation of these new relationships, which did not receive strong bootstrap supports (Fig. 3), awaits further taxon sampling of mitogenomic and/or nuclear gene data.

\section{Historical biogeography}

Previous studies on the historical biogeography of Acrodonta did not necessarily postulate the monophylies of Agamidae and Iguanidae. Thus, terms such as the origins of Iguania, Acrodonta and Agamidae have been confusingly used. This study provided strong evidence for the monophylies of Agamidae and Iguanidae, with which previous biogeographic hypotheses can be reevaluated. Here, we discuss the acrodontan biogeography based on molecular, paleontological and geological evidence without a priori assumption of vicariance or dispersal (see Fig. 6).

There have been two major hypotheses on the origin of Acrodonta, i.e., where the most recent common ancestor of Agamidae and Chamaeleonidae was, either Laurasian or Gondwanan. Occurrence of acrodontan priscagamid (and even pleurodont iguanian) fossils from mid-late Cretaceous of Asia (Fig. 6.3) led some researchers to hypothesize Laurasian (more specifically Central Asian or Mongolian) origin of Iguania and Acrodonta (e.g., [54,55]). A recent report of a gliding acrodont lizard (Xianglong) from Early Cretaceous of China [56] may also support this idea. Extant agamid lizards are distributed primarily in Eurasia but some occur in Australasia and Africa. Recent molecular phylogeny ([12,25,50,57]; but see $[13,58])$ is consistent with a view that extant Agamidae originated from Asia and that some descendant lineages (e.g., Amphibolurinae and Uromastycinae) dispersed to Australasia and Africa during Cenozoic times when they were geographically connected to or in close proximity to Eurasia. On the other hand, there is good agreement in Gondwanan (more specifically Madagascan or African) origin of extant chamaeleonids $[5,6,14,59]$. Taken together, the Laurasian origin of Acrodonta requires the long-distance transmarine dispersal of chamaeleonid ancestors from Eurasia to Madagascar/Africa.

Gondwanan origin of Iguania was proposed by Estes [60] based on some fossil evidence and the basal divergence of Iguania from Scleroglossa, which is not tenable by recent molecular phylogeny. Macey et al. [13] used molecular phylogeny to advocate the Gondwanan origin of Acrodonta and proposed that major acrodontan lineages diverged vicariantly and/or migrated to the Northern Hemisphere by plate tectonics (i.e., collision of Indian subcontinent or other Gondwanan land blocks to Eurasia). Although a recent molecular study [17] further supported the out-of-India radiation of a subfamily Agaminae, other molecular studies $[25,50,57]$ questioned the Gondwanan vicariance or multiple northward migrations for at least some lineages (e.g., Amphibolurinae and Uromastycinae).

More recently, some fossil evidence shed a light on this issue. Bharatagama from Early-Middle Jurassic Kota Formation of India (Fig. 6.2) represents the oldest record of early acrodont iguanians [61]. This fossil record may support the Gondwanan origin of acrodonts [47,61]. If acrodonts did originate from Gondwanaland, it is consistent with the likely Gondwanan origin of Iguanidae sensu lato ([18]; refs. therein) but ancestors of extant agamids, which were postulated to be in Asia (see above), may 
Table 2: Comparison of different phylogenetic hypotheses within Chamaeleonidae

\begin{tabular}{cccccc}
\hline Tree & log $\mathbf{~}$ & difference & S.E. & p-KH' & p-SH \\
& & & & & $1.000+$ \\
\hline Tree1 & -182540.58 & 0 & best & $1.000+$ & $0.001-$ \\
Tree2 & -182640.62 & 100.04 & 23.7 & $0.000-$ & $0.030-$ \\
Tree3 & -182594.41 & 53.83 & 20.57 & $0.006-$ & $0.002-$ \\
Tree4 & -182637.55 & 96.97 & 29.64 & $0.000-$ & $0.001-$ \\
Tree5 & -182610.7 & 70.12 & 23.27 & $0.001-$ & $0.137+$ \\
Tree6 & -182575.68 & 35.1 & 16.09 & $017-$ & 0.00 \\
\hline
\end{tabular}

1Probabilities by the Kishino-Hasegawa test

2Probabilities by the Shimodaira-Hasegawa test

Values with a minus mean 'rejective' in the $5 \%$ level

Tree1 : Bayesian tree from this study (Fig. 3)

Tree2 : Topology consistent with Klaver and Böhme [5]

Tree3 : Topology consistent with Raxworthy et al. [14]

Tree4 : Topology consistent with Townsend and Larson [15]

Tree5 : Bayesian tree reconstructed using a combined data set from Raxworthy et al. [14] and Townsend and Larson [15]

Tree6 : Bayesian tree reconscructed with the mitogenomic data set by constraining the monophyly of Chamaeleo + Trioceros

See Additional File 2 for Newick representations for each tree.

need to have migrated from the Southern to Northern Hemisphere by transmarine dispersal.

The present study (Fig. 4) suggested that Agamidae and Chamaeleonidae are each monophyletic and that they diverged from each other in the mid-Cretaceous (96-122 MYA) although independent molecular dating using nuclear genes suggested somewhat younger dates around 85 MYA [42]. Okajima and Kumazawa [18] previously showed that the appreciable gap in the estimated divergence time of oplurine iguanids between mitochondrial [18] and nuclear [62] gene sequences could be due to multiple factors, such as differences in the tree topology and time constraints assumed for each study, the intrinsic data property of mitochondrial and nuclear sequences, and relatively poor squamate fossil records [47] that can be used to constrain ingroup squamate divergences precisely.

In spite of this somewhat low precision of time estimation, the molecular dating results (Fig. 4; [42]) consistently suggest that Agamidae and Chamaeleonidae were separated after the Middle-Late Jurassic break-up of Pangea into Laurasia and Gondwanaland (Fig. 6.2) and when the latter two supercontinents were further fragmented by plate tectonics [63]. Geological data suggest that India and Madagascar were drifted from Gondwanaland in the Early Cretaceous (120-130 MYA)(Fig. 6.3) and separated from each other in the Late Cretaceous ( 90 MYA)(Fig. 6.4)[63]. Then, India moved northward and accreted to Eurasia from the latest Cretaceous to Eocene (Fig. 6.5) [63].

Assuming Gondwanan origin of Acrodonta, the molecular dating results (96-122 MYA from Fig. 4 and $~ 85$
MYA from [42] for the divergence of Agamidae and Chamaeleonidae) are consistent with a view that Agamidae vicariantly diverged from Chamaeleonidae on the India/Madagascar landmass. It may be further hypothesized that Agamidae migrated to Eurasia on the drifting Indian subcontinent (Fig. 6.5) while Chamaeleonidae was left within Madagascar and its descendants migrated to Africa over Mozambique Channel and later to Eurasia (Fig. 6.6). Molecular dating (Fig. 4) suggested that extant chamaeleonid genera diverged during Cenozoic times. Some of them are distributed exclusively in Madagascar (Furcifer, Calumma and Brookesia) while the others are distributed in Africa (Rhampholeon/Rieppeleon and Bradypodion/Kinyongia/Nadzikambia) or in Africa + Eurasia (Chamaeleo/Trioceros). Because Africa and Madagascar had been clearly separated in the Cenozoic [63], generic radiations of chamaeleonids cannot be associated with Gondwanan vicariance. As previous authors postulated $[14,15]$, chamaeleonids are likely to have experienced transmarine dispersal over Mozambique Channel multiple times. To the best of our knowledge, the oldest certain fossil record of Chamaeleonidae is Chamaeleo caroliquarti from western Bohemia [64]. Africa had long been isolated from other continents but connected to Eurasia in the Miocene [63]. Thus, occurrence of this fossil in the Miocene of Europe is consistent with the above-mentioned biogeographic explanation.

Molecular dating (Fig. 4) also suggested that extant agamid subfamilies diverged from each other in the Late Cretaceous. If Agamidae did migrate to Eurasia on India as hypothesized above, the dating result suggests that subfamilial radiations of agamids occurred on the drifting 

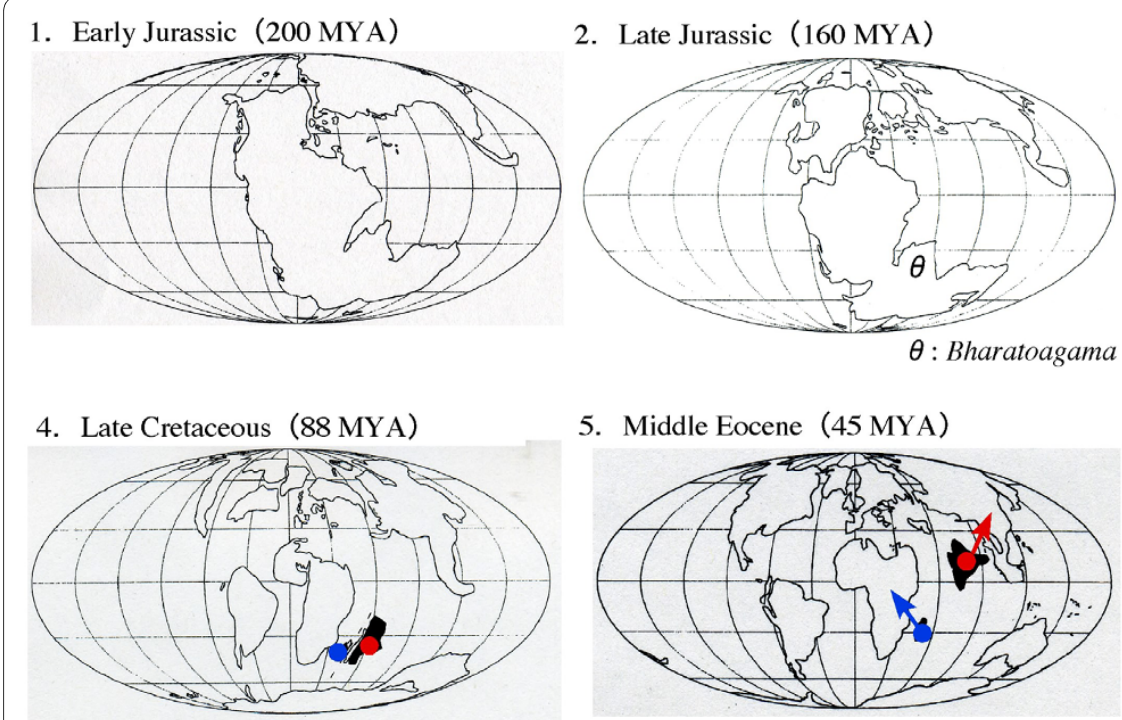

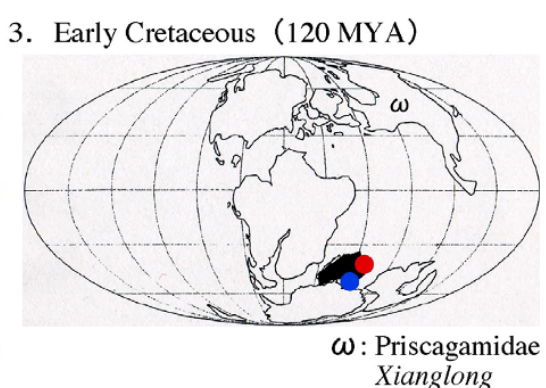

6. Early Miocene (20 MYA)

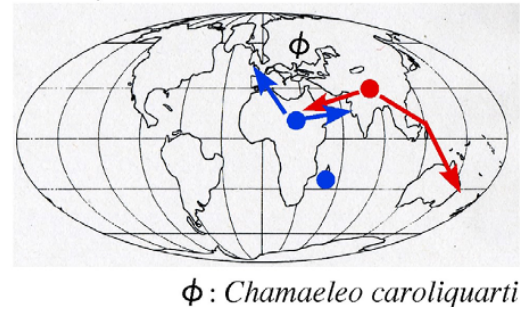

Figure 6 The historical biogeography of acrodont lizards based on the molecular, paleontological and geological evidence. Paleogeographical maps at six different times [63] are shown on which a hypothesis on the origin and migration pathways for agamids (red) and chamaeleonids (blue) is illustrated. The earliest fossil records for acrodonts and chameleons are, respectively, Early-Middle Jurassic (165 - 200 MYA) Bharatoagama from the Kota Formation of India [61] and Miocene ( 26 MYA) Chamaeleo caroliquarti from Bohemia [64]. Acrodont fossils of Priscagamidae are found from Aptian-Albian (100 - 120 MYA) and Campanian ( 80 MYA) Central Asia and Mongolia [43,54,55]. Another acrodont fossil of a gliding lizard Xianglong is found from Early Cretaceous of China [56].

Indian subcontinent. This may sound somewhat unlikely but this is not impossible under the assumption that a number of ancient agamid lineages radiated, dispersed locally in Asia, and became extinct. Vastanagama susani and Tinosaurus indicus from the Early Eocene of India are known as the earliest certain agamid fossils in South Asia [65].

Then, how can this hypothesis based on Gondwanan origin of extant acrodont groups reconcile with the early Cretaceous Xianglong and mid-late Cretaceous priscagamid acrodonts from Laurasian sites (Central Asia and Mongolia)? Xianglong and priscagamids are stem acrodont lizards which are unlikely to be nested within extant agamids but their exact phylogenetic positions are not yet known $[56,66]$. Therefore, they probably diverged from a long branch of stem acrodonts 110-200 MYA (see Fig. 4). These extinct groups may be Laurasian relics of acrodont lizards which had diverged from Gondwanan acrodonts (i.e., direct common ancestors of extant agamids and chamaeleonids) before Pangean break-up into Laurasia and Gondwanaland. Alternatively, they may simply have derived from the Gondwanan ancestors by transmarine dispersal.

\section{Conclusions}

In the present study, mitogenomic sequences collected from major acrodontan lineages were analyzed in comparison with iguanid counterparts. We detected distinct modes of mitogenomic evolution among iguanian fami- lies. Agamidae was highlighted in including a number of lineage-specific mitochondrial gene rearrangements and Chamaeleonidae was found to have a much longer CR sequences. Although mitogenomes of these two families appear to evolve at accelerated rates, they still retain certain conserved features in CR sequences.

Our mitogenomic data provided a certain level of resolution in reconstructing acrodontan phylogeny, although there still remain ambiguous relationships. The strong support for the agamid monophyly should influence taxonomic treatment of the metataxon Agamidae and the suggested separation of Trioceros from Chamaeleo would support elevation of these taxa to distinct genera [46]. More resolution in unsettled acrodontan phylogenies should be sought by sequencing and comparing considerably longer regions of nuclear genomes than ever.

In this study acrodontan biogeography was reevaluated mostly in favor of Gondwanan origin of Acrodonta, which was originally proposed by Estes [60] and Macey et al. [13]. We suggest that the whole extant Agamidae may have migrated to Eurasia with India. However, we do not agree to the possibility that all or most of agamid subfamilies were introduced to Eurasia, Australasia or Africa by the accretion of Gondwanan plates at different times [13].

Finally, we should carefully state that molecular data and our arguments presented herein do not strictly rule out the Laurasian origin of Acrodonta [54,55] under the assumption that the long-distance transmarine dispersal of chamaeleonid ancestor(s) from Laurasian sites to Mad- 
agascar/Africa was possible by unknown geological settings. Further efforts in testing these hypotheses, including ours, by diverse approaches should be encouraged in future.

\section{Methods Samples}

Animal samples except for Pseudotrapelus sinaitus were obtained from local animal dealers as dead specimens, identified for their species name, and registered to public museums or the Specimen Depository of a university (Table 1). Samples for P. sinaitus were collected at Bir Abraq, Egypt. Total DNA was extracted from a tiny amount of tissue samples either with a DNeasy Tissue kit (Qiagen) or by the procedure of Asahida et al. [67]. When multiple individuals were available for the same species, we chose an individual having the best DNA quality for sequencing the entire mitogenome. We then used another individual for sequencing short mtDNA regions to confirm that mtDNA sequences from the second individual are identical or nearly identical to those from the first individual. This is a test for the reliability and reproducibility of our experiments.

\section{Mitochondrial DNA sequencing}

Determination of complete mtDNA sequences was carried out essentially as described previously [19]. Several pairs of reptile-oriented primers [19] were used to amplify and sequence different gene segments of $\mathrm{mtD}$ NAs. Species-specific primers (data not shown) were then designed in these regions for amplifying longer parts of the mtDNA by the long PCR using LA-Taq or Z-Taq (Takara, Inc). We typically covered the entire mtDNA by a few overlapping long PCR products. The long-PCR products were used as templates for nested PCR amplifications using the various reptile-oriented primers with ZTaq, giving rise to overlapping $0.6-1.3 \mathrm{kbp}$ products. The complete mtDNA sequences were unambiguously determined by sequencing and assembling these shorter PCR products. For some of the species, the CR contained extensive tandem repeats and we could not sequence a part of the CR (see Table 1).

\section{Gene identification and data alignment}

Protein gene sequences were translated into amino acid sequences with the vertebrate mitochondrial genetic code [36]. The starting and ending sites of these genes were determined by comparison with the corresponding genes from other vertebrates and in consideration of the possible creation of the stop codon by polyadenylation. Transfer RNA genes were identified based on their secondary structure models [30]. Ranges of the small and large rRNA genes were tentatively identified by tRNA genes that surround them. The major noncoding region was regarded as the CR as it contains CSBs [37]. In this way, all 37 genes and the CR were identified for each of the new mtDNA sequences.

Nucleotide sequences for each of the 37 genes were aligned among the newly sequenced 10 taxa and 39 other vertebrates (see Table 1 and Additional File 3 for their taxon names and accession numbers). The MacClade alignment files for each of the 37 genes can be obtained from authors upon request. We used a script written by Mr. Pierre Jonniaux and Dr. Takamasa Suzuki, with which individual genes of the reported mitogenomic sequences were automatically taken from the databases into a fasta file. This facilitated quick and accurate sequence manipulations. Note that Kinyongia fischeri mtDNA has recently been sequenced by Macey et al. [29] independently and that we used our K. fischeri mtDNA sequence for subsequent analyses. Also note that Brookesia superciliaris mtDNA sequence reported by Macey et al. [29] was not used due to its incompleteness ( 12 kbp). The outgroup taxa were selected from one or two representatives from major vertebrate groups, such as Amphibia, Mammalia, Aves, Gekkota and Anguimorpha, except for possibly non-monophyletic Scincomorpha (3 representatives). We omitted some taxa (e.g., snakes and dibamids) that have not been placed in the squamate phylogeny securely when estimated with complete mitogenomic sequences $[21,28,39,68]$.

Protein gene sequences were aligned first for their amino acid sequences with the aid of ClustalX [69], with which nucleotide sequences were automatically aligned using the 'Import NBRF Protein Alignment' function of MacClade 4 (Sinauer Associates, Inc). Transfer RNA and rRNA genes were aligned with the aid of their secondary structure models [30,70]. Nucleotide sequences of the first and second codon positions of 12 heavy-strandencoded protein genes (except for the light-strandencoded ND6 gene due to its deviated nucleotide and amino acid compositions), 22 tRNA genes, and 2 rRNA genes were concatenated for 31 iguanians and 18 noniguanian vertebrates. At the level of deep-branch phylogenies of this study, nucleotides at third codon positions clearly accumulate considerable multiple hits (data not shown) and they were removed from phylogenetic analyses. Because the mitochondrial genome of the tuatara lacks three genes including the largest protein-coding gene for ND5 [71], phylogenetic analyses were primarily conducted without the tuatara after removing all gapcontaining sites (48 taxa, 9,386 sites in total).

\section{Phylogenetic analyses}

The Bayesian method was mainly used for constructing phylogenetic relationships. For the Bayesian analyses, MrBayes v3.12 [72] was used with the GTR+I+G model selected by MrModeltest 2.2 [73] after separating the data 
into four partitions (first codon positions, second codon positions, rRNA positions and tRNA positions). Four chains were run simultaneously by Markov chain Monte Carlo (MCMC) process until the ASDSF (average standard deviation of split frequency) index [72] becomes less than 0.01 (2,500,000 generations). After the initial one fourth of the generations were discarded based on the stationarity of the MCMC process at this stage, 18,750 trees were collected from every 100 generations. The 50\% majority -rule consensus tree was created from this tree pool and the Bayes-PP values (the frequency of a specific phylogenetic relationship in the sampled tree population) were obtained as a statistical measure for resultant phylogenetic relationships.

We conducted several phylogenetic analyses using different representative taxa from each major group of vertebrates to confirm that taxon selection in the outgroup does not basically change ingroup acrodont relationships (data not shown). As one of such analyses, the Bayesian tree reconstructed with another taxon, the tuatara (Additional File 4), showed the same acrodont relationships as in Fig. 3 although a polytomy occurred with respect to subfamilial relationships of Iguanidae sensu lato. We also tested some different partition schemes including the one categorizing protein genes into four different enzyme complexes [68] to confirm that our phylogenetic tree was not affected by such partition scheme (data not shown).

Bootstrap probabilities were assessed by the ML method using GARLI0.96b8 [74] with the GTR+I+G model. The same dataset as used for the Bayesian analysis was supplied without partitioning and 500 replications were carried out. Statistical evaluation of alternative phylogenetic hypotheses was done with TREE-PUZZLE 5.2 [75] using the Kishino-Hasegawa [76] and ShimodairaHasegawa [77] tests. The GTR+I+G model and its parameters optimized by MrModeltest 2.2 were used.

\section{Estimation of divergence times}

Divergence times were estimated with the multidistribute program [48] by assuming a topological relationship thus obtained but without assuming the strict molecular clock. The program PAML [78] was first used to optimize parameters for the F84 nucleotide substitution model and the gamma distribution for 8 categories for each of the four partitions separately. The estbranches/multidivtime programs were then run by the Bayesian MCMC method to provide posterior distributions of divergence times at each internal node. Several parameters set to run the MCMC analyses were: numsamps, 10,000; sampfreq, 100; burnin, 100,000; rttm and rttmsd, 4.3; rtrate and rtratesd, 0.05 ; and brownmean and brownmeansd, 0.2 . The coelacanth (Latimeria chalumnae) was used as an outgroup in this analysis. We conducted the divergence time estimation with different settings for taxon samplings (e.g., more sparse sampling from Iguanidae and non-iguanians), time constraints (i.e., addition/deletion of some of the seven time constraints used) and some parameters (e.g., brownmean/brownsd and bigtime) to confirm that results were essentially the same.

Similar time constraints for divergence times as used by Okajima and Kumazawa [18] were employed. They are based on relatively reliable fossil-based time constraints for several representative nodes: Amphibia vs. Amniota, $340<$ T $<370$ MYA; Synapsida vs. Sauropsida (Reptiles + Aves), 288<T<338 MYA; Archosauria vs. Lepidosauria, $255<\mathrm{T}<305$ MYA; Aves vs. Crocodylia, 240<T<260 MYA; Acrodonta vs. Pleurodonta, $165<\mathrm{T}$ MYA; and origin of Scincomorpha, $160<\mathrm{T}$ MYA. Refer to Okajima and Kumazawa [18] and Kumazawa [28] for references that justify these time constraints. In addition to these time constraints, we also included a time constraint for a shallower divergence between African and Arabian chameleons within genus Chamaeleo. The time constraint for this divergence $(5<\mathrm{T}<13$ MYA) was based on the biogeographic assumption that they diverged vicariantly by the expansion of Red Sea [29] (see [50] for geological evidence for this time range).

\section{Additional material}

Additional file 1 Alignment of control region sequences from iguanians and other vertebrates.

Additional file $\mathbf{2}$ Topological relationships assumed for the KishinoHasegawa and Shimodaira-Hasegawa tests in table2.

Additional file 3 Non-iguanian outgroup taxa analyzed for their complete mtDNA sequence.

Additional file $4 \mathrm{~A}$ Bayesian tree reconstructed using mitogenomic nucleotide sequences by including the tuatara and retaining gapcontaining sites (49 taxa, 9689 sites).

\section{Authors' contributions}

$Y O$ contributed to sequencing mitochondrial genomes. $Y O$ and $Y K$ analyzed the data and wrote the manuscript. Both authors read the manuscript and agreed to its publication.

\section{Acknowledgements}

This paper is dedicated, with our sincerest gratitude, to Dr. Sayed A. M. Amer who was a visiting professor from Cairo University to Nagoya University and now is a professor of Taif University, Saudi Arabia. He sequenced mitochondrial genomes of four agamids, found the anticodon switch in A. armata tRNAPro gene, and actively participated in the discussion of our results. We are sorry that he finally hesitated to become an author because of his religious belief We also thank Mr. Kosho Yagi (Remix Peponi) and Fuji 3A Project for providing animal samples, Ms. Chieko Aoki for experimental assistance, and Dr. Susan

Evans for information on fossils and biogeography. Our gratitude is extended to Mr. Pierre Jonniaux and Dr. Takamasa Suzuki for bioinformatic contributions to handling and editing molecular datasets. We are indebted to Prof. Shigeru Itoh's warm and continuous encouragement during our study at Nagoya University. Thoughtful comments and suggestions from four reviewers, the Associate Editor and the Science Editor are cordially appreciated. This study was funded by the Ministry of Education, Culture, Sports, Science and Technology of Japan (grant Nos. 17570076 and 20370033) to YK, the Japan Society for the Promotion of Science (to Dr. Sayed A. M. Amer), and the 21 st Century/Global Center of Excellence programs at the Division of Biological Science, Nagoya University (to YO). 


\section{Author Details}

'Division of Biological Science, Graduate School of Science, Nagoya University, Furo-cho, Chikusa-ku, Nagoya 464-8602, Japan and 2Department of Information and Biological Sciences, Graduate School of Natural Sciences, Nagoya City University, 1 Yamanohata, Mizuho-cho, Mizuho-ku, Nagoya 4678501, Japan

Received: 3 November 2009 Accepted: 13 May 2010

Published: 13 May 2010

\section{References}

1. Pough FH, Andrews RM, Cadle JE, Crump ML, Savitzky AH, Wells KD: Herpetology. Third edition. London: Pearson Education; 2004.

2. Estes R, de Queiroz R, Gauthier J: Phylogenetic relationships within Squamata. In Phylogenetic relationships of the lizard families Edited by: Estes R, Pregill G. Stanford, California, USA: Stanford University Press; 1988:119-281

3. Moody SM: Phylogenetic and historical biogeographical relationships of the genera in family Agamidae (Reptilia: Lacertilia). In PhD Thesis Ann Arbor, Michigan: University of Michigan; 1980.

4. Böhme W: Über Schmetterlingsagamen, Leiolepis belliana belliana, der malayischen Halbinsel und ihre parthenogenetischen Linien (Sauria, Uromastycidae). Zoologische Jahrbücher, Abteilung für Systematik, Ökologie und Geographie der Tiere 1982, 109:157-169.

5. Klaver CJ, Böhme W: Phylogeny and classification of the Chamaeleonidae (Sauria) with special reference to hemipenis morphology. Bonn Zool Monogr 1986, 22:1-64.

6. Rieppel O: The phylogenetic relationships within the Chamaeleonidae, with comments on some aspects of cladistic analysis. Zool J Linn SoC 1987, 89:41-62.

7. Frost $D R$, Etheridge R: A phylogenetic analysis and taxonomy of iguanian lizards (Reptilia: Squamata). Univ Kansas Mus Nat Hist Misc Publ 1989, 81:1-65

8. Schwenk K: Systematics and subjectivity: the phylogeny and classification of iguanian lizards revisited. Herpetol Rev 1994, 25:53-57.

9. Lee MS: Soft anatomy, diffuse homoplasy, and the relationships of lizards and snakes. Zool Script 2000, 29:101-130.

10. Macey JR, Larson A, Ananjeva NB, Papenfuss TJ: Evolutionary shifts in three major structural features of the mitochondrial genome among iguanian lizards. J Mol Evol 1997, 44:660-674.

11. Schulte JA II, Macey JR, Larson A, Papenfuss TJ: Molecular tests of phylogenetic taxonomies: a general procedure and example using four subfamilies of the lizard family Iguanidae. Mol Phylogenet Evol 1998, 10:367-376.

12. Honda M, Ota H, Kobayashi M, Nabhitabhata J, Yong H-S, Sengoku S, Hikida T: Phylogenetic relationships of the family Agamidae (Reptilia: Iguania) inferred from mitochondrial DNA sequences. Zool Sci 2000, 17:527-537.

13. Macey JR, Schulte JA II, Larson A, Ananjeva NB, Wang Y, Pethiyagoda R, Rastegar-Pouyani N, Papenfuss TJ: Evaluating trans-Tethys migration: an example using acrodont lizard phylogenetics. Syst Bio/ 2000, 49:233-256.

14. Raxworthy CJ, Forstner MRJ, Nussbaum RA: Chameleon radiation by oceanic dispersal. Nature 2002, 415:784-787.

15. Townsend TM, Larson A: Molecular phylogenetics and mitochondrial genomic evolution in the Chamaeleonidae (Reptilia, Squamata). Mol Phylogenet Evol 2002, 23:22-36.

16. Townsend TM, Larson A, Louis E, Macey JR: Molecular phylogenetics of Squamata: the position of snakes, amphisbaenians, and dibamids, and the root of the squamate tree. Syst Biol 2004, 53:735-757.

17. Melville J, Hale J, Mantziou G, Ananjeva NB, Milto K, Clemann N: Historical biogeography, phylogenetic relationships and intraspecific diversity of agamid lizards in the Central Asian deserts of Kazakhstan and Uzbekistan. Mol Phylogenet Evol 2009, 53:99-112.

18. Okajima $Y$, Kumazawa $Y$ : Mitogenomic perspectives into iguanid phylogeny and biogeography: Gondwanan vicariance for the origin of Madagascan oplurines. Gene 2009, 441:28-35.

19. Kumazawa $\mathrm{Y}$, Endo H: Mitochondrial genome of the Komodo dragon: efficient sequencing method with reptile-oriented primers and novel gene rearrangements. DNA Res 2004, 11:115-125.

20. Wolstenholme DR: Animal mitochondrial DNA: structure and evolution. Int Rev Cytol 1992, 141:173-216.
21. Castoe TA, de Koning AP, Kim HM, Gu W, Noonan BP, Naylor G, Jiang ZJ, Parkinson CL, Pollock DD: Evidence for an ancient adaptive episode of convergent molecular evolution. Proc Natl Acad Sci USA 2009, 106:8986-8991.

22. Boore JL: Animal mitochondrial genomes. Nucleic Acids Res 1999 27:1767-1780

23. Macey JR, Larson A, Ananjeva NB, Fang Z, Papenfuss TJ: Two novel gene orders and the role of light-strand replication in rearrangement of the vertebrate mitochondrial genome. Mol Biol Evol 1997, 14:91-104.

24. Amer SAM, Kumazawa Y: The mitochondrial genome of the lizard Calotes versicolor and a novel gene inversion in South Asian draconine agamids. Mol Biol Evol 2007, 24:1330-1339.

25. Amer SAM, Kumazawa Y: Mitochondrial genome of Pogona vitticepes (Reptilia; Agamidae): control region duplication and the origin of Australasian agamids. Gene 2005, 346:249-256.

26. Macey JR, Schulte JA II, Fong JJ, Das I, Papenfuss TJ: The complete mitochondrial genome of an agamid lizard from the Afro-Asian subfamily Agaminae and the phylogenetic position of Bufoniceps and Xenagama. Mol Phylogenet Evol 2006, 39:881-886.

27. Ujvari B, Dowton M, Madsen T: Mitochondrial DNA recombination in a free-ranging Australian lizard. Biol Lett 2007, 3:189-192.

28. Kumazawa Y: Mitochondrial genomes from major lizard families suggest their phylogenetic relationships and ancient radiations. Gene 2007, 388:19-26.

29. Macey JR, Kuehl JV, Larson A, Robinson MD, Ugurtas IH, Ananjeva NB, Rahman H, Javed HI, Osman RM, Doumma A, Papenfuss TJ: Socotra Island the forgotten fragment of Gondwana: Unmasking chameleon lizard history with complete mitochondrial genomic data. Mol Phylogenet Evol 2008, 49:1015-1018

30. Kumazawa Y, Nishida M: Sequence evolution of mitochondrial tRNA genes and deep-branch animal phylogenetics. J Mol Evol 1993, 37:380-398

31. Osawa S, Jukes TH, Watanabe K, Muto A: Recent evidence for evolution of the genetic code. Microbiol Rev 1992, 56:229-264.

32. Janke A, Erpenbeck D, Nilsson M, Arnason U: The mitochondrial genomes of the iguana (Iguana iguana) and the caiman (Caiman crocodylus): implications for amniote phylogeny. Proc R Soc Lond B 2001, 268:623-631.

33. Kumazawa Y: Mitochondrial DNA sequences of five squamates: phylogenetic affiliation of snakes. DNA Res 2004, 11:137-144.

34. Macey JR, Schulte JA II, Larson A: Evolution and phylogenetic information content of mitochondrial genomic structural features illustrated with acrodont lizards. Syst Biol 2000, 49:257-277.

35. Sbisà E, Tanzariello F, Reyes A, Pesole G, Saccone C: Mammalian mitochondrial D-loop region structural analysis: identification of new conserved sequences and their functional and evolutionary implications. Gene 1997, 205:125-140.

36. Anderson S, Bankier AT, Barrell BG, de Bruijn MHL, Coulson AR, Drouin J, Eperon IC, Nierlich DP, Roe BA, Sanger F, Schreier PH, Smith AJH, Staden R, Young IG: Sequence and organization of the human mitochondrial genome. Nature 1981, 290:457-465.

37. Walberg MW, Clayton DA: Sequence and properties of the human KB cell and mouse $L$ cell D-loop regions of mitochondrial DNA. Nucleic Acids Res 1981, 9:5411-5421.

38. Brehm A, Harris DJ, Alves C, Jesus J, Thomarat F, Vicente L: Structure and evolution of the mitochondrial DNA complete control region in the lizard Lacerta dugesii (Lacertidae, Sauria). J Mol Evol 2003, 56:46-53.

39. Douglas DA, Arnason U: Examining the utility of categorical models and alleviating artifacts in phylogenetic reconstruction of the Squamata (Reptilia). Mol Phylogenet Evol 2009, 52:784-96.

40. Vidal N, Hedges SB: The phylogeny of squamate reptiles (lizards, snakes, and amphisbaenians) inferred from nine nuclear protein-coding genes. CR Biol 2005, 328:1000-1008.

41. Hugall AF, Foster R, Lee MSY: Calibration choice, rate smoothing, and the pattern of tetrapod diversification according to the long nuclear gene RAG-1. Syst Biol 2007, 56:543-563.

42. Hedges SB, Vidal N: Lizards, snakes, and amphisbaenians (Squamata). In The timetree of life Edited by: Hedges SB, Kumar S. Oxford, England: Oxford University Press; 2009:383-389.

43. Borsuk-Bialynicka M, Moody SM: Priscagaminae, a new subfamily of the Agamidae (Sauria) from the Late Cretaceous of the Gobi Desert. Acto Palaeontol Polonica 1984, 29:51-81. 
44. Matthee CA, Tilbury CR, Townsend T: A phylogenetic review of the African leaf chameleons: genus Rhampholeon (Chamaeleonidae): the role of vicariance and climate change in speciation. Proc R Soc Lond $B$ 2004, 271:1967-1975.

45. Tilbury CR, Tolley KA, Branch WR: A review of the systematics of the genus Bradypodion (Sauria: Chamaeleonidae), with the description of two new genera. Zootaxa 2006, 1363:23-38.

46. Tilbury CR, Tolley KA: A re-appraisal of the systematics of the African genus Chamaeleo (Reptilia: Chamaeleonidae). Zootaxa 2009, 2079:57-68

47. Evans SE: At the feet of the dinosaurs: the early history and radiation of lizards. Biol Rev 2003, 78:513-551.

48. Thorne JL, Kishino H, Painter IS: Estimating the rate of evolution of the rate of molecular evolution. Mol Biol Evol 1998, 15:1647-1657.

49. Böhme MU, Fritzsch G, Tippmann A, Schlegel M, Berendonk TU: The complete mitochondrial genome of the green lizard Lacerta viridis viridis (Reptilia: Lacertidae) and its phylogenetic position within squamate reptiles. Gene 2007, 394:69-77.

50. Amer SAM, Kumazawa Y: Mitochondrial DNA sequences of the AfroArabian spiny-tailed lizards (genus Uromastyx; family Agamidae): phylogenetic analyses and evolution of gene arrangements. Biol J Linn Soc 2005, 85:247-260.

51. Townsend TM, Vieites DR, Glaw F, Vences M: Testing species-level diversification hypotheses in Madagascar: the case of microendemic Brookesia leaf chameleons. Syst Bio/ 2009, 58:641-656.

52. Schulte JA II, Cartwright EM: Phylogenetic relationships among iguanian lizards using alternative partitioning methods and $T S H Z 1$ : A new phylogenetic marker for reptiles. Mol Phylogenet Evol 2009, 50:391-396.

53. Joger U: A molecular phylogeny of agamid lizards. Copeia 1991, 1991:616-622.

54. Alifanov VR: Some peculiarities of the Cretaceous and Palaeogene lizard faunas of the Mongolian People's Republic. Kaupia 1993, 3:9-13.

55. Gao K, Hou L-H: Iguanians from the Upper Cretaceous Djadochta Formation, Gobi Desert, China. J Vert Paleontol 1995, 15:57-78.

56. Li P-P, Gao K-Q, Hou L-H, Xu X: A gliding lizard from the Early Cretaceous of China. Proc Natl Acad Sci USA 2007, 104:5507-9.

57. Hugall AF, Lee MSY: Molecular claims of Gondwanan age for Australian agamid lizards are untenable. Mol Biol Evol 2004, 21:2102-2110.

58. Schulte JA II, Melville J, Larson A: Molecular phylogenetic evidence for ancient divergence of lizard taxa on either side of Wallace's Line. Proc $R$ Soc Lond B 2003, 270:597-603.

59. Hofman A, Maxson LR, Arntzen W: Biochemical evidence pertaining to the taxonomic relationships within the family Chamaeleonidae. Amphibia-Reptilia 1991, 12:245-265.

60. Estes R: The fossil record and early distribution of lizards. In Advances in herpetology and evolutionary biology Edited by: Rhodin AGJ, Miyata K. Cambridge, Massachusetts: Museum of Comparative Zoology, Harvard University; 1983:365-398.

61. Evans SE, Prasad GVR, Manhas BK: Fossil lizards from the Jurassic Kota formation of India. J Vert Paleontol 2002, 22:299-312.

62. Noonan BP, Chippindale PT: Vicariant origin of Malagasy reptiles supports Late Cretaceous Antarctic land bridge. Am Nat 2006, 168:730-741.

63. Smith AG, Smith DG, Funnell BM: Atlas of Mesozoic and Cenozoic coastlines. New York: Cambridge University Press; 1994.

64. Moody SM, Rocek Z: Chamaeleo caroliquarti (Chamaeleonidae, Sauria): a new species from the lower Miocene of central Europe. Vestnik Ustredniho Ustavu Geol 1980, 55:85-92.

65. Prasad GVR, Bajpai S: Agamid lizards from Early Eocene of western India: oldest Cenozoic lizards from South Asia. Palaeontologia Electronica 2008, 11:4A

66. Alifanov VR: The fossil record of Cretaceous lizards from Mongolia. In The age of dinosaurs in Russia and Mongolia Edited by: Benton MJ, Shishkin MA, Unwin DM, Kurochkin EN. New York: Cambridge University Press; 2000:368-389.

67. Asahida T, Kobayashi T, Saitoh K, Nakayama I: Tissue preservation and total DNA extraction from fish stored at ambient temperature using buffers containing high concentration of urea. Fish Sci 1996, 62:727-730.

68. Albert EM, San Mauro D, García-París M, Rüber L, Zardoya R: Effect of taxon sampling on recovering the phylogeny of squamate reptiles based on complete mitochondrial genome and nuclear gene sequence data. Gene 2009, 441:12-21.

69. Thompson JD, Gibson TJ, Plewniak F, Jeanmougin F, Higgins DG: The ClustalX windows interface: flexible strategies for multiple sequence alignment aided by quality analysis tools. Nucleic Acids Res 1997, 25:4876-4882.

70. Wuyts J, Perrière G, Peer $Y$ Van de: The European ribosomal RNA database. Nucleic Acids Res 2004, 32:D101-D103.

71. Rest JS, Ast JC, Austin CC, Waddell PJ, Tibbetts EA, Hay JM, Mindell DP Molecular systematics of primary reptilian lineages and the tuatara mitochondrial genome. Mol Phylogenet Evol 2003, 29:289-297.

72. Ronquist F, Huelsenbeck JP: MRBAYES 3: Bayesian phylogenetic inference under mixed models. Bioinformatics 2003, 19:1572-1574.

73. Nylander JAA: MrModeltest v2. Program distributed by the author. Evolutionary Biology Centre, Uppsala University; 2004.

74. Zwickl DJ: Genetic algorithm approaches for the phylogenetic analysis of large biological sequence datasets under the maximum likelihood criterion. In Ph.D. dissertation The University of Texas at Austin; 2006.

75. Schmidt HA, Strimmer K, Vingron M, von Haeseler A: TREE-PUZZLE: maximum likelihood phylogenetic analysis using quartets and parallel computing. Bioinformatics 2002, 18:502-504.

76. Kishino $H$, Hasegawa M: Evaluation of the maximum likelihood estimate of the evolutionary tree topologies from DNA sequence data, and the branching order in Hominoidea. J Mol Evol 1989, 29:170-179.

77. Shimodaira H, Hasegawa M: Multiple comparison of log-likelihood with applications to phylogenetic inference. Mol Biol Evol 1999, 16:1114-1116

78. Yang Z: PAML: a program package for phylogenetic analyses by maximum likelihood. CABIOS 1997, 13:555-556.

doi: $10.1186 / 1471-2148-10-141$

Cite this article as: Okajima and Kumazawa, Mitochondrial genomes of acrodont lizards: timing of gene rearrangements and phylogenetic and bio geographic implications BMC Evolutionary Biology 2010, 10:141

\section{Submit your next manuscript to BioMed Central and take full advantage of:}

- Convenient online submission

- Thorough peer review

- No space constraints or color figure charges

- Immediate publication on acceptance

- Inclusion in PubMed, CAS, Scopus and Google Scholar

- Research which is freely available for redistribution

Submit your manuscript at www.biomedcentral.com/submit
C) Biomed Central 